\title{
L1CAM-ILK-YAP Mechanotransduction Drives Proliferative Activity of Epithelial Cells in Middle Ear Cholesteatoma
}

\author{
Tomomi Yamamoto-Fukuda, ${ }^{*}$ Naotaro Akiyama, ${ }^{\dagger}$ and Hiromi Kojima*
}

From the Department of Otorhinolaryngology, ${ }^{*}$ Jikei University School of Medicine, Tokyo; and the Department of Otorhinolaryngology, ${ }^{\dagger}$ Toho University School of Medicine, Tokyo, Japan

\author{
Accepted for publication \\ April 15, 2020. \\ Address correspondence to \\ Tomomi Yamamoto-Fukuda, \\ M.D., Ph.D., Department of \\ Otorhinolaryngology, Jikei \\ University School of Medicine, \\ 3-25-8, Nishishinbashi, Minato- \\ ku, Tokyo, 105-8461, Jap- \\ an. E-mail: tomomiyf@jikei. \\ ac.jp.
}

\begin{abstract}
Middle-ear cholesteatoma (cholesteatoma) is a chronic otitis media with an enhanced proliferation of epithelial cells. Negative pressure in the middle ear is thought to be important for the etiology of cholesteatoma. However, the mechanism of cholesteatoma formation remains unclear. Integrin-linked protein kinase (ILK), an important modulator of actin cytoskeletal dynamics, interacts with extracellular matrix and results in the up-regulation of mechanotransduction effector Yes-associated protein (YAP). The L1 cell adhesion molecule (L1CAM) has recently been reported as an activator of the mechanotransduction effectors related to cell proliferation and migration. In this study, we demonstrated a stretch assay for middle-ear cultured cells and performed immunohistochemistry using antibodies against Ilk, Yap, and L1cam. The tympanic membrane was also analyzed within a new middleear negative-pressure animal model and human cholesteatoma tissues, using immunohistochemistry with antibodies against ILK, YAP, Ki-67, and L1CAM. The expression of cytoplasmic ILK and nuclear shift of YAP increased in the thickened epithelium of the tympanic membrane under a negativepressure load and the cholesteatoma. The expression of L1CAM was detected in the stromal cells, which enhanced epithelial cell proliferation depending on ILK signaling events. In conclusion, we demonstrated the possibility that the stromal L1CAM and epithelial ILK-YAP signaling played an important role in epithelial growth under mechanotransduction in cholesteatoma formation. (Am J Pathol 2020, 190: 1667-1679; https://doi.org/10.1016/j.ajpath.2020.04.007)
\end{abstract}

Middle-ear cholesteatoma (cholesteatoma) is a chronic otitis media that usually grows into the middle ear with bone distraction, eventually causing hearing loss. Negative pressure in the middle ear can be an important pathogenic factor in the development of chronic conditions of the middle ear, such as retraction and atrophy of the tympanic membrane (TM), persistent middle-ear effusion, adhesive otitis media, and cholesteatoma. ${ }^{1,2}$

Yes-associated protein (YAP) is known to be a sensor of mechanical stimuli, including matrix stiffness, stretch, and cell density, and it controls cell proliferation and differentiation, fibrosis, and cancer metastasis. ${ }^{3,4}$ When mechanical tension has occurred by the stretching of a cell, the shape of the extracellular matrix changes some molecular components of the focal adhesions to induce YAP nuclear translocation and to reactivate cell proliferation. ${ }^{5,6}$
Integrin-linked protein kinase (ILK) is an integrinassociated actin and tubulin cytoskeletal interacting effector. ${ }^{7}$ ILK regulates several cell adhesion and integrinmediated, as well as growth factor-regulated functions and also induces nuclear accumulation of YAP as a negative regulator of the Hippo pathway. ${ }^{8}$

The L1 cell adhesion molecule (L1CAM), a key member of the immunoglobulin-like CAM family, was first recognized as playing a critical role in the surface interactions of neurons by binding with each other and with extracellular matrix proteins. ${ }^{9}$ In earlier studies, L1CAM expression was

Supported by Japanese Society for the Promotor of Science (JSPS) KAKENHI Grant Numbers JP16K11186 (T.Y.-F.), JP19K09857 (T.Y.-F.) and JP18K16908 (N.A.).

Disclosures: None declared. 
shown to be present during tumorigenicity, proliferation, invasion, and metastasis in cancers. ${ }^{10,11}$ Recently, Er et al ${ }^{12}$ indicated L1CAM-mediated metastatic cell outgrowth with L1CAM-ILK signaling. They showed that L1CAM expressed in the pericyte attached to a tumor cell activates ILK signaling, resulting in the up-regulation of mechanotransduction effectors YAP in the tumor cell.

Consequently, we speculated that mechanical cues induced by high negative pressure might accelerate YAP signaling through stromal L1CAM-epithelial ILK signaling and thus lead to the proliferation of epithelial cells in cholesteatoma. To investigate this hypothesis, a stretch assay was conducted using a primary culture of middle-ear epithelial cells from ICR mice, and a negative-pressure animal model was developed. ${ }^{13,14}$ The expression of ILK and YAP nuclear translocation in epithelial cells and L1CAM expression in human cholesteatoma tissues, noncholesteatomatous chronic otitis media (COM) tissues, and normal skin tissues were analyzed and compared with their labeling indexes (LIs). Finally, double immunofluorostaining of L1CAM and ILK was performed in human cholesteatoma tissues and z-stack images were taken using fluorescence confocal laser scanning microscopy to prove the epithelial cell-stromal cell interaction. The correlation between the L1CAM expression level (low, moderate, high) or the distance between the $\mathrm{L} \mathrm{CAM}{ }^{+}$cells and proliferating epithelium (L1CAM distance), and Ki-67 LI of the cholesteatoma tissues was analyzed. There was a significant correlation between the expression level of L1CAM and $\mathrm{Ki}$ $67 \mathrm{LI}$ and the level of L1CAM distance and Ki-67 LI. These results indicate the possible involvement of both stromal L1CAM and ILK ${ }^{+} /$YAP nuclear translocated epithelial cells in enhanced epithelial cell proliferative activity of cholesteatoma under mechanotransduction.

\section{Materials and Methods}

\section{Stretch Assay of ICR Mice Middle-Ear Epithelial Cells and Treatments}

Middle-ear epithelial cells for the stretch assay were prepared from ICR mice (10 ears) by the primary explant culture described previously. ${ }^{15}$ The cells were subcultured up to the third passage and plated in a deformable silicon membrane of the silicone elastomer polydimethylsiloxane chambers (STB-CH-4W; Strex, Osaka, Japan) coated with $0.05 \%$ porcine type I collagen (Cellmatrix Type I-P; Nitta Gelatin Inc., Osaka, Japan) ${ }^{16}$ at an initial density of $1.0 \times 10^{5} \mathrm{cells} / \mathrm{cm}^{2}$. They were allowed to attach and reach a state of about $70 \%$ confluency for 2 days before applying stretch. ${ }^{17}$ The medium was replaced with low-glucose (1000 mg/L) Dulbecco's modified Eagle's medium containing $0.1 \%$ fetal bovine serum (DMEM/0.1\% FBS) 6 hours before the cells were subjected to stretch. ${ }^{18}$ Uniaxial cell stretching was applied using a cell-stretching device (Strex ST-140; Strex) by $150 \%$ of their original length for 2 or 24 hours (stretched group, $n=4) .{ }^{16-19}$ In the control group $(n=4)$, the cells in the chambers were not subjected to stretching. To analyze the effects of soluble L1CAM against proliferative activities of stretching cells, the culture medium was replaced with DMEM/0.1\% FBS with recombinant mouse (rm) L1CAM $(30 \mu \mathrm{g} / \mathrm{mL})$ (R\&D, Minneapolis, MN) ${ }^{20}$ (stretched with rm L1CAM group, $n=4$ ) or replaced with DMEM/0.1\% FBS without rm L1CAM (stretched without rm L1CAM group, $n=4) 6$ hours before the cells were subjected to stretch or nonstretched for 24 hours.

\section{Animal Model Induction of Continuous Negative Pressure in the Middle Ear of a Rat}

Male Sprague-Dawley rats (8 weeks old) were used. All experiments were conducted according to the principles and procedures outlined in the guidelines for animal experimentation of Nagasaki University (Nagasaki, Japan) with the approval of the Institutional Animal Care and Use Committee (numbers 1209241015-2 and 1404011269). Continuous negative pressure in the right middle ear was generated through the supply route of a micro infusion pump (iPrecio; Primetech Corp., Tokyo, Japan) (negativepressure group, $n=4)$, according to the protocol of a previous paper. ${ }^{13}$ Negative pressure $(-14.8 \pm 15.9 \mathrm{~mm} \mathrm{Hg})$ was given continuously over 24 hours for 5 consecutive days per week. ${ }^{13}$ All of the left ears were nontreated and used as controls $(n=5) \cdot{ }^{13}$ A total of $22 \mathrm{U} / \mathrm{g}$ per day penicillin $\mathrm{G}$ was administered by i.m. injection for 7 days after surgery. ${ }^{13}$ At 7 days after surgery, an otoendoscopic examination of the TMs was performed using a thin endoscope system (model AE-R16060; AVS, Tokyo, Japan) and the rats were euthanized. ${ }^{13}$ The temporal bones were collected, fixated, decalcified, and embedded in paraffin in the standard manner. ${ }^{21}$ The sections $(5 \mu \mathrm{m}$ thick $)$ were prepared and some were stained with hematoxylin and eosin for histologic examination as previously described. ${ }^{13}$

\section{Patients, Specimen Harvest, and Tissue Preparation}

The cholesteatoma tissue samples ( 21 men, 4 women; mean age, 39 years; range, 10 to 69 years) and COM tissue samples (10 men, 3 women; mean age, 57 years; range, 20 to 75 years) were confirmed by histopathologic examination. All of the patients were treated surgically and the tissues were harvested from the patients during surgery at the Department of Otorhinolaryngology, Jikei University Hospital (Tokyo, Japan), between May 2016 and December 2019. From the ears of the study subjects with cholesteatoma, a small piece of normal skin was also harvested. This study protocol was approved by the Human Ethics Review Committee of the Jikei University School of Medicine, and signed informed consent was obtained from all of the patients or their guardians for this study (approval number 27-344 8229). Sample fixation and serial section (5 $\mu \mathrm{m}$ thick) preparation was done in the standard manner. ${ }^{22}$ 
For the histologic examination, hematoxylin and eosin staining was performed using a standard procedure.

\section{IHC}

For the detection of L1CAM, ILK, YAP, and Ki-67 in the primary cultured cells, fluorescence immunohistochemistry (IHC) was performed as described previously. ${ }^{14,23}$ For the detection of L1CAM, ILK, YAP, and Ki-67 on the paraffin sections, an enzyme or fluorescence IHC was performed as described previously. ${ }^{14,22,23}$ All of the antibodies used in this study are listed in Table 1 . The sections were deparaffinized with toluene and rehydrated with serially graded ethanol solutions. Antigen retrieval was performed by autoclaving in Tris/EDTA buffer (pH 9.0) at $120^{\circ} \mathrm{C}$ for 10 minutes for L1CAM or in HistoVT one at $90^{\circ} \mathrm{C}$ for 20 minutes for Ki-67, ILK, and YAP, then blocked with 500 $\mu \mathrm{g} / \mathrm{mL}$ normal goat $\mathrm{IgG}$ in $1 \%$ bovine serum albumin in phosphate-buffered saline for 1 hour at room temperature. The slides were incubated overnight with the first antibodies (Table 1). After they were washed with $0.05 \%$ Tween 20 in phosphate-buffered saline, the slides were reacted with the appropriate secondary antibody (Table 1). After being washed with $0.05 \%$ Tween 20 in phosphate-buffered saline, the horseradish peroxidase sites were visualized with diaminobenzidine and $\mathrm{H}_{2} \mathrm{O}_{2}$. For fluorescent staining, the slides were counterstained with DAPI and visualized by fluorescence conjugate. For a negative control, normal mouse $\operatorname{IgG}(1: 100)$ or normal rabbit $\operatorname{IgG}(1: 100)$ was used instead of the first antibodies, respectively, in each experiment. To identify the $\mathrm{ILK}^{+}$and $\mathrm{YAP}^{+}$cells, double staining was performed on the paraffin sections. ${ }^{24}$ After deparaffinization, the slides were stained with a first antibodies mixture (rabbit anti-ILK antibody and mouse anti-YAP antibody) (Table 1) and immersed with the appropriate secondary antibodies (Table 1). Horseradish peroxidase sites were visualized with diaminobenzidine and $\mathrm{H} 2 \mathrm{O} 2$ and the alkaline phosphatase sites were visualized with Warp Red solution (Biocare Medical, Concord, CA).

\section{Western Blot Analysis}

The cells $\left(4.0 \times 10^{5}\right.$ cells $)$ were washed with ice-cold phosphate-buffered saline and lysed using buffer $[2 \times$ Laemmli buffer (Bio-Rad, Hercules, CA) and 2-mercaptoethanol, protein/phosphatase inhibitor (Cell Signaling Technology, Danvers, MA)]. Cell lysates were centrifuged twice at $13,523 \times g$ for 5 minutes at $4^{\circ} \mathrm{C}$. Proteins were then separated by polyacrylamide gel (Thermo Fisher Scientific, Dreieich, Germany) and transferred electrophoretically onto polyvinylidene difluoride membranes (Immobilon-P; Millipore, Bedford, MA). The membranes were blocked with 5\% skim milk (Cell Signaling) in $0.1 \%$ Tween 20 in Tris-buffered saline for 1 hour at room temperature and immerse with first antibodies (Table 1) diluted in a $2.5 \%$ blocking buffer at $4^{\circ} \mathrm{C}$ overnight. The antibody-antigen complexes were detected using horseradish peroxidase goat anti-mouse $\operatorname{IgG}$ or rabbit IgG (1:10,000 dilution) (Table 1) for 1 hour at room temperature. The signals were visualized by the ECL system (ECL Prime; GE Healthcare, Chicago, IL) and photographs were taken using a chemiluminescence imager (LAS 4000; GE Healthcare). A quantification data analysis was performed using ImageJ software version 15.1 (NIH Bethesda, MD; https://imagej.nih.gov/ij) ${ }^{25}$ and the signal strength was determined using the intensity of the band divided by the $\beta$-actin band intensity, establishing $\beta$-actin protein levels as a loading control.

\section{Microscopy, Image Analysis, and Cell Count}

Images of the hematoxylin and eosin staining and enzyme immunostaining were captured using an Axio Cam camera and AxioVision software version 4.8 (Carl Zeiss, Jena,

Table 1 Antibodies Used for Immunostaining

\begin{tabular}{|c|c|c|c|}
\hline Antigen, clone name or immunogen & Manufacturer, species, catalog no. & Dilution used & Type \\
\hline ILK, human ILK aa. 326-452 & BD Biosciences (San Jose, CA), rabbit, 611803 & $1: 50$ or $1: 1000$ & Primary \\
\hline YAP, human YAP aa. $100-150$ & Bioworld Technology Inc. (Louis Park, MN), rabbit, BS1701 & $1: 100$ & Primary \\
\hline Yap 63.7 & Santa Cruz Biotechnology, Inc. (Santa Cruz, CA), mouse, sc-101199 & $1: 50$ & Primary \\
\hline L1CAM, EPR18750 & Abcam (Cambridge, UK), rabbit, ab208155 & $1: 200$ & Primary \\
\hline L1cam, 2C2 & Abcam, mouse, ab24345 & $1: 500$ & Primary \\
\hline HRP-goat anti-rabbit IgG & Abcam, goat, ab6721 & $1: 100$ & Secondary \\
\hline HRP-goat anti-mouse IgG & Cell Signaling Technology, mouse, 7076 & $1: 10000$ & Secondary \\
\hline HRP-goat anti-rabbit IgG & Cell Signaling Technology, rabbit, 7074 & $1: 10000$ & Secondary \\
\hline Mach 2-HRP-goat anti-mouse IgG & Biocare Medical (Concord, CA) & - & Secondary \\
\hline Mach 2-AP-goat anti-rabbit IgG & Biocare Medical & - & Secondary \\
\hline
\end{tabular}

AP, alkaline phosphatase; HRP, horseradish peroxidase; ILK, integrin linked protein kinase; L1cam, L1 cell adhesion molecule; YAP, Yes-associated protein. 
Germany) under light microscopy. Fluorescence images were obtained using fluorescence confocal laser scanning microscopy (LSM 880; Carl Zeiss). For the double staining of ILK and L1CAM, each section was extracted as a $0.5-\mu \mathrm{m}$ z-stack with confocal laser scanning microscopy (LSM 880). For the quantitative analysis, the enzyme IHC results were graded as positive or negative as compared with the negative control, and the number of cell nuclei was counted at $>1000$ nuclei in three equal epithelial regions at $\times 400$ magnification. Per specimen of immunofluorostaining, three $10,000-\mu \mathrm{m}^{2}$ areas $(100 \times 100-\mu \mathrm{m}$ squares) for the equal epithelial regions were assumed with confocal laser scanning microscopy (LSM 880) and Zeiss acquisition analysis software (Zen 2.1 black edition), and the number of positive cell nuclei was counted. DAPI labeling was used to obtain the total cell number. L1CAM distance was measured between the $\mathrm{L} \mathrm{CAM}^{+}$cells and proliferating epithelium at three locations (central and at each extreme) using ImageJ software.

\section{Statistical Analysis}

Means and SDs were calculated from numeric data. Differences between the groups were examined for statistical significance using the one-way analysis of variance test followed by the unpaired $t$-test or Tukey post hoc test for
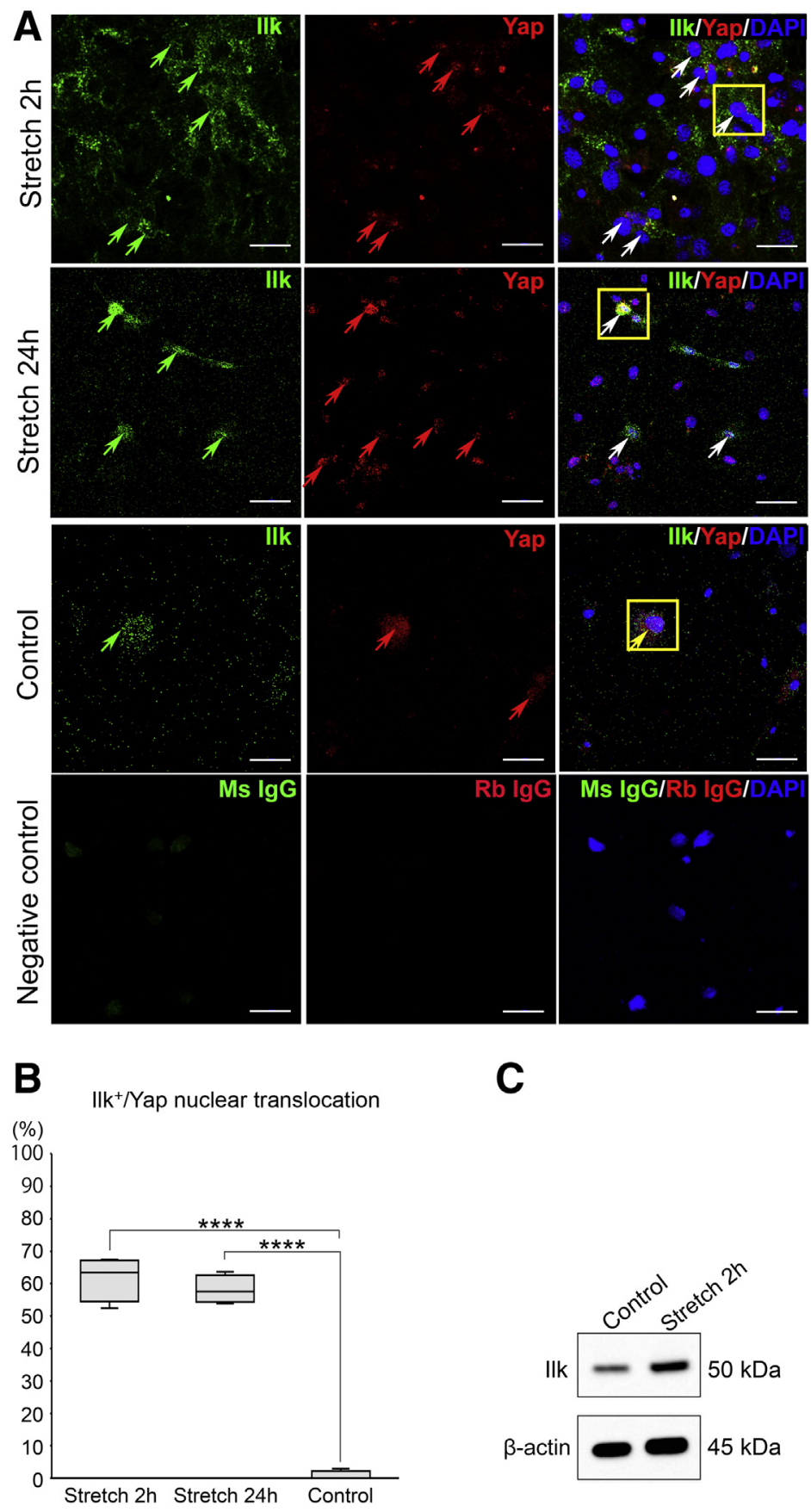
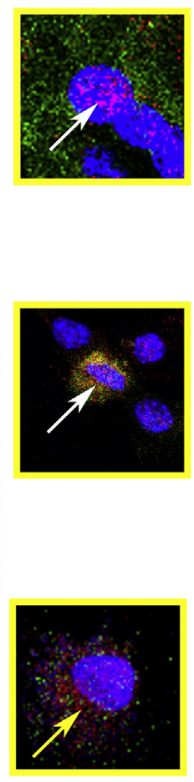

Figure 1 A: Continuous stretch-induced integrin-linked protein kinase (Ilk) expression in cytoplasm and Yes-associated protein (Yap) nuclear translocation. Double immunofluorescence detection of Ilk (green) and Yap (red) in mouse epithelial cells stretched for 2 or 24 hours or nonstretched (control). Ilk expression is observed in many cells of 2-hour stretch and some cells of 24-hour stretch (green arrows). Yap expression is observed in many cells of 2- and 24-hour stretch, and in some cells of the control (red arrows). The expression of Ilk and Yap nuclear translocation is observed in the cells of 2- and 24-hour stretch (white arrows). Ilk and Yap expression levels are observed in cytoplasm of some cells of the control group (yellow arrows). Boxed areas are shown at higher magnification to the right. Negative control was obtained by normal mouse (Ms) IgG and normal rabbit $(\mathrm{Rb}) \mathrm{IgG}$ instead of first antibodies. The nuclei were stained with DAPI (blue). B: Labeling index (LI) of Ilk ${ }^{+}$/Yap nuclear translocation in the cells of 2- and 24-hour stretch versus control. C: Western blot analysis of Ilk and $\beta$-actin in the cells of control (left lane) or 2-hour stretch (right lane) (top lane, reacted with anti-Ilk antibody; bottom lane, reacted with anti- $\beta$-actin antibody). $\beta$-Actin was used as a loading control. Data are expressed as means \pm SD. Error bars indicate $95 \%$ confidence interval. $n=4$ per group. ${ }^{* * * * P}<0.0001$. Scale bars $=20 \mu \mathrm{m}$. 

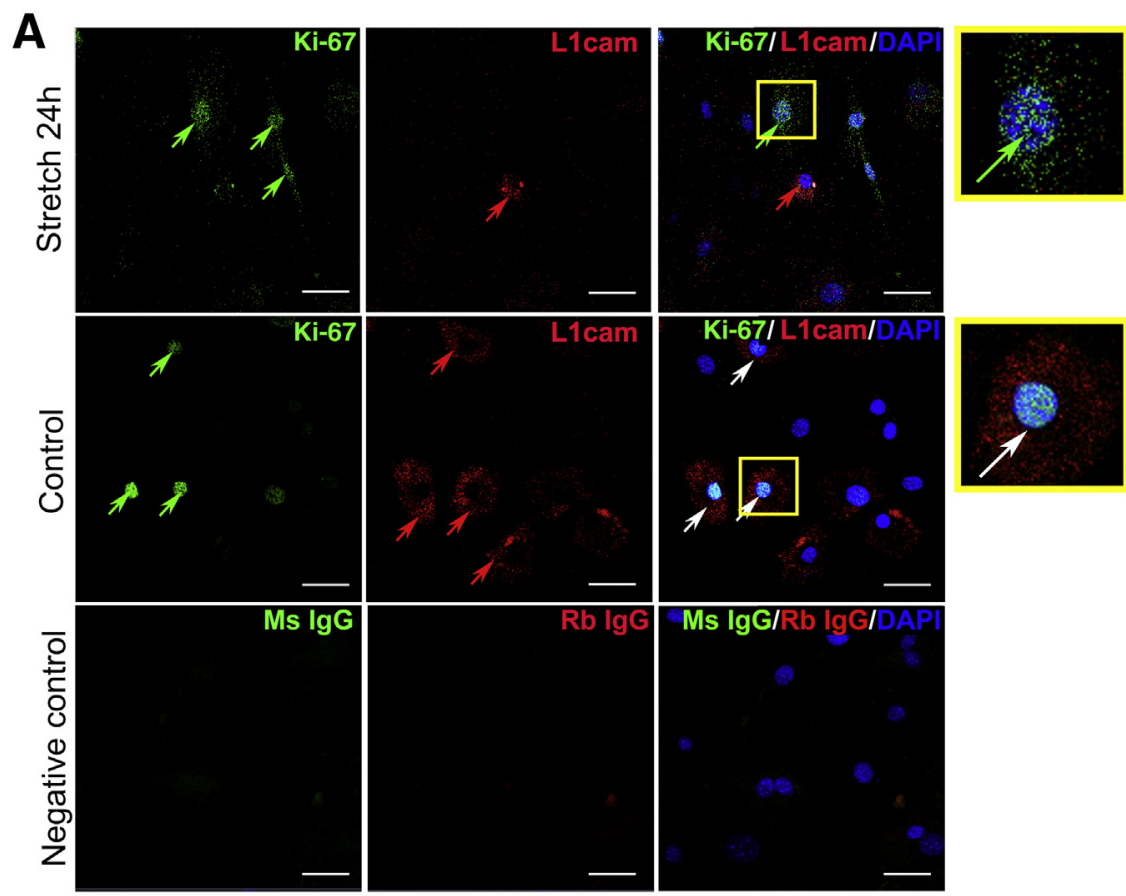

B

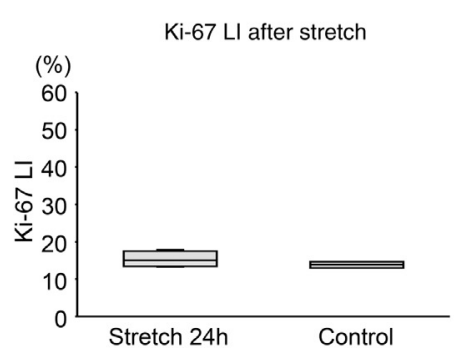

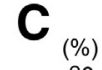

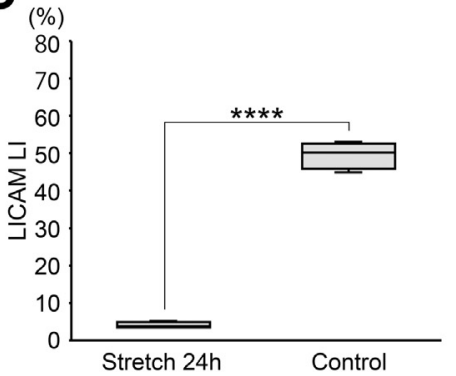

Figure 2 A: Double immunofluorescence of Ki67 (green) and L1 cell adhesion molecule (L1cam) (red) in mouse epithelial cells stretched for 24 hours or nonstretched (control). L1cam expression is observed in many cells of the control and in some cells of 24-hour stretch (red arrows). Ki-67 cells (green arrows) are detected both in the control and 24-hour stretch. White arrows indicate $\mathrm{Ki}-67^{+} / \mathrm{L} 1 \mathrm{cam}^{+}$cells. Boxed areas are shown at higher magnification to the right. Negative control was obtained by normal mouse (Ms) IgG and normal rabbit $(\mathrm{Rb}) \mathrm{IgG}$ instead of first antibodies. The nuclei were stained with DAPI (blue). B and C: Ki-67 (B) and L1cam (C) labeling index (LI) in cells of 24-hour stretch versus control. Data are expressed as means \pm SD. Error bars indicate $95 \%$ confidence interval. $n=4$ per group. $* * * * P<0.0001$. Scale bars $=20 \mu \mathrm{m}$. normally distributed data. A $P$ value of $<0.05$ denoted a statistically significant difference. All analyses were performed using JMP statistical software package version 13 (SAS Institute Japan, Tokyo, Japan).

\section{Results}

Uniaxial Stretch and Up-Regulation of Ilk and Yap Nuclear Translocation in Middle-Ear Mouse Epithelial Cells

As expected, continuous stretch in epithelial cells induced Ilk expression in the cytoplasm following the activation of Yap translocation from the cytoplasm to the nucleus. According to the double staining with Ilk and Yap, many $\mathrm{Ilk}^{+}$cells were detected and most had Yap nuclear translocation in the section of the stretched group ( 2 hours, 24 hours) (Figure 1A). On the other hand, a small number of $\mathrm{Ilk}^{+}$cells were detected, and Yap was detected in the cytoplasm of the cells in the section of the control group (Figure 1A). The LI of the $\mathrm{Ilk}^{+}$and Yap nuclear-translocated cells was significantly increased in the stretched group (2 hours, 24 hours) compared to that in the control group [2-hour stretch versus control, $61.7 \pm 6.89$ versus $0.76 \pm 1.52(P<0.0001) ; 24$-hour stretch versus control, $58.1 \pm 4.32$ versus $0.76 \pm 1.52$ $(P<0.0001)$; Tukey post hoc test] (Figure 1B). Anti-Ilk polyclonal antibody detected Ilk protein with a $50-\mathrm{kDa}$ band in the control group and stretched group (2 hours) (Figure 1C). The intensity of the band of the stretched group was higher than that of the control group (2-hour stretch versus control, 0.56 versus 0.36 ). These data suggest that uniaxial stretch causes up-regulation of Ilk in middle-ear epithelial cells.

Uniaxial Stretch, L1cam Expression, and Proliferation Activity in Mouse Epithelial Cells

According to the double staining of L1cam and Ki-67, L1 cam ${ }^{+}$cells were scarcely detected and some Ki- $67^{+}$cells were detected in the section of the stretched group (24 hours) (Figure 2A). On the other hand, almost all of the cells 


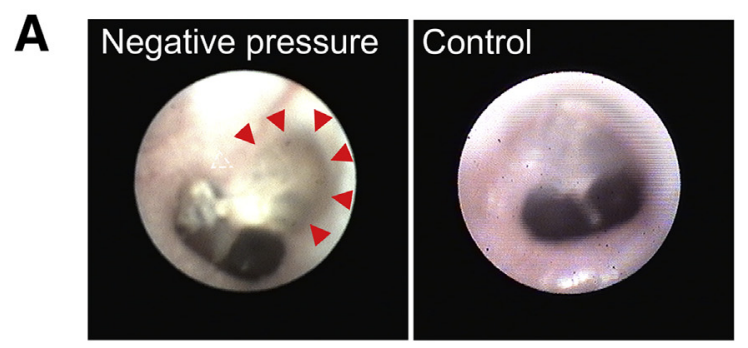

B Negative pressure Control
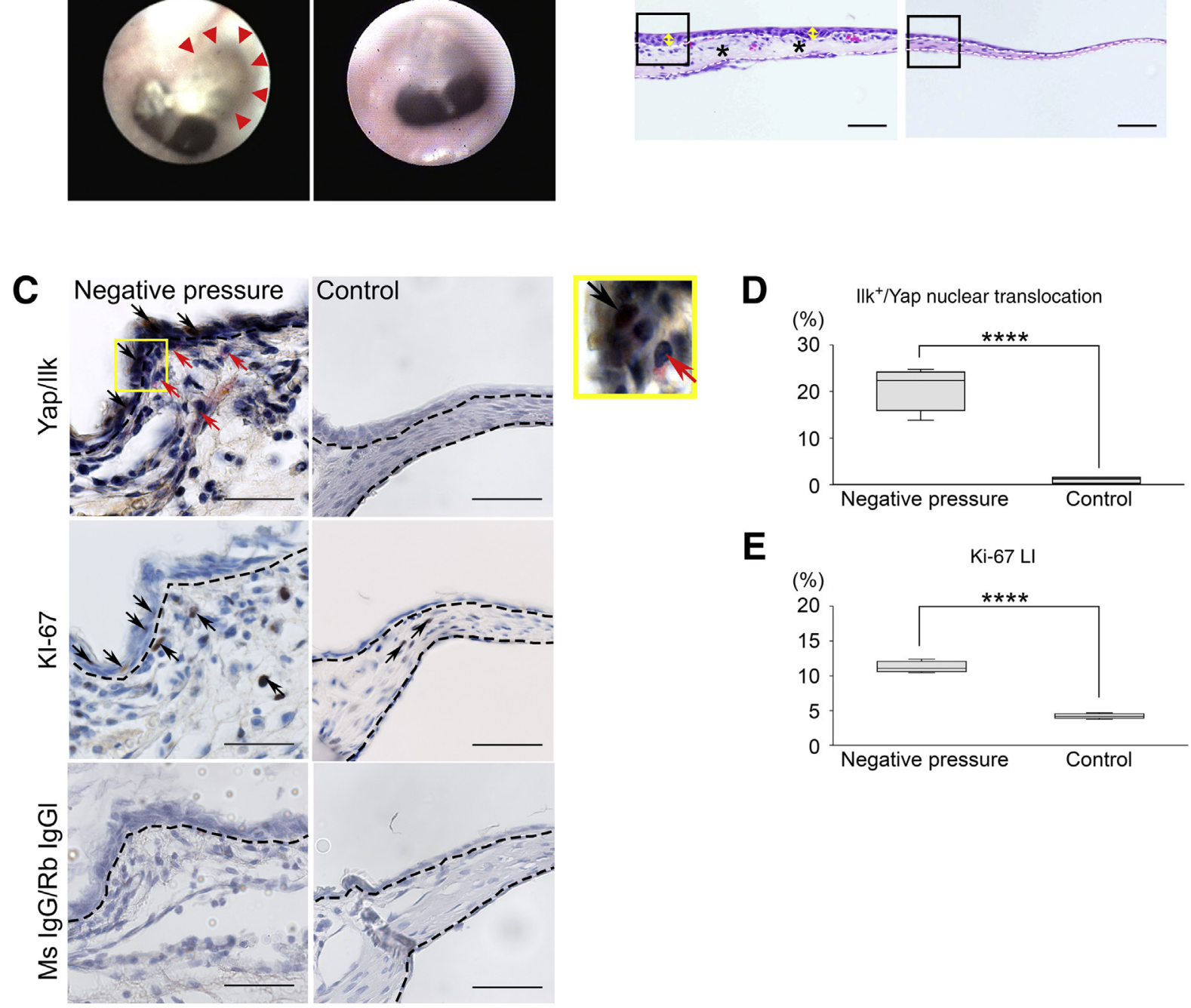

\section{E}
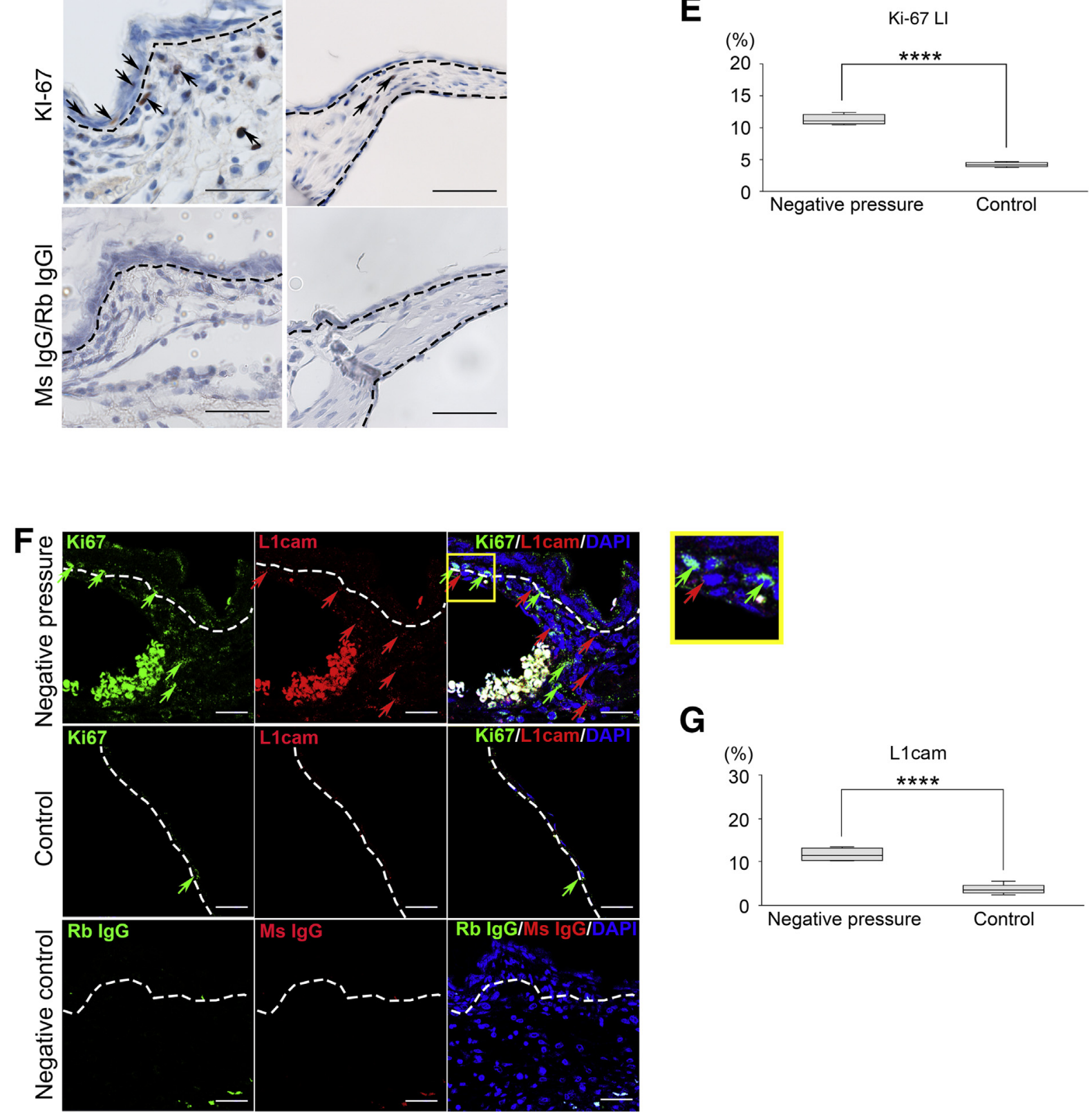

G

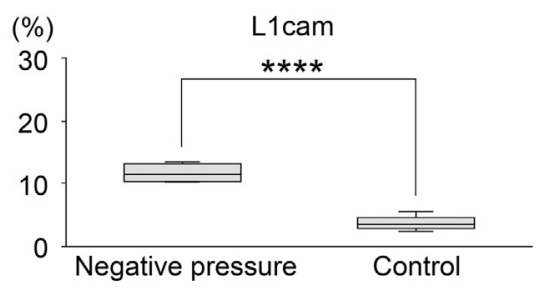


were $\mathrm{L} 1 \mathrm{cam}^{+}$and some $\mathrm{Ki}-67^{+}$cells were detected in the section of the control group (Figure 2A). The Ki-67 LI of the stretched group was similar to that of the control group (24-hour stretch versus control, $15.3 \pm 2.21$ versus $13.8 \pm 0.93 ; P=0.2643, t$-test) (Figure 2B). The L1cam LI of the stretched group was significantly decreased compared to that of the control group (24-hour stretch versus control, $3.9 \pm 0.78$ versus $49.6 \pm 3.57 ; P<0.0001, t$-test) (Figure 2C).

\section{Negative Pressure in a Rat Middle Ear and Up- Regulation of Ilk, Yap Nuclear Translocation, L1cam Expression, and Epithelial Cell Proliferation in Epithelial Cells of the TM}

Ilk-Yap signaling was analyzed in the epithelium of the TM under continuous negative pressure in vivo. An otoendoscopic examination revealed that the TMs of all of the negative-pressure ears were retracted and that the control ears had a normal TM appearance, similar to the results described previously (Figure 3A). ${ }^{3}$ Hematoxylin and eosin staining revealed that the epithelial and intermediate layers of the pars flaccida of the TMs of the negative-pressure ears were thickened, although the mucosal layer appeared as normal simple squamous epithelium (Figure 3B). In this thickened TM, the number of $\mathrm{Ilk}^{+}$cells had increased in the epithelial and intermediate layers. Some of the $\mathrm{Ilk}^{+}$cells had Yap nuclear translocation in the basal and upper layers of the epithelium (Figure 3C). In the control ears, $\mathrm{Ilk}^{+} / \mathrm{Yap}^{+}$ cells were scarcely detected (Figure 3C). The LI of $\mathrm{Ilk}^{+} / \mathrm{Yap}$ nuclear-translocated epithelial cells had significantly increased in the negative-pressure-load ears compared to that of the control ears $(11.6 \% \pm 1.93 \%$ versus $1.67 \% \pm 0.50 \% ; P<0.0001, t$-test) (Figure 3D). These findings indicate that continuous negative pressure in the TM induces Ilk expression in the cytoplasm following the activation of Yap nuclear translocation in the basal and upper layers of the epithelial region. On the other hand, $\mathrm{Ki}-67^{+}$cells were detected in the basal layer of the epithelium and intermediate layer of TMs of the negativepressure ears (Figure 3C). Among $\mathrm{Ilk}^{+} /$Yap nucleartranslocated epithelial cells of continuous negative pressure, $\mathrm{Ki}-67^{+}$cells were observed in the basal layer of the epithelium (Figure 3C). In the epithelial layer of the controls, $\mathrm{Ki}-67^{+}$cells were rarely detected (Figure $3 \mathrm{C}$ ). The Ki67 LI of the epithelial cells in the TM of the negativepressure-load ears was significantly higher compared to that of the controls $(11.2 \% \pm 0.81 \%$ versus $4.20 \% \pm 0.35 \% ; P<0.0001, t$-test) (Figure 3E).

Continuous negative pressure in the TM induced L1cam expression in the cells of the intermediate layer and increased $\mathrm{Ki}-67 \mathrm{LI}$ in the epithelium. In the TM of the control, $\mathrm{L} 1 \mathrm{cam}^{+}$cells were scarcely detected in any of the

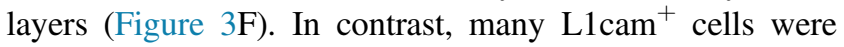
detected in the thickened intermediate layer of the TM under a negative pressure load, but not in the epithelial layers (Figure 3F). The L1cam LI of the stromal cells in the TM of the negative-pressure-load ears was significantly higher compared to that of the control ears $(11.6 \% \pm 1.50 \%$ versus $3.68 \% \pm 1.15 \% ; P<0.0001, t$-test) (Figure 3G). A double IHC analysis for Ki-67 and L1cam was performed to evaluate the effects of L1cam and Ilk-Yap signaling on the proliferative activity of the epithelial cells. In the epithelial layer of the controls, $\mathrm{Ki}-67^{+}$cells were rarely found (Figure 3F). In the thickened epithelial region of the TM under a negative pressure load, the number of $\mathrm{Ki}-67^{+}$cells was increased in the basal layer (Figure 3F) and L1 $\mathrm{cam}^{+}$ cells were observed near the Ki-67 ${ }^{+}$cells (Figure 3F).

\section{Expression of ILK and YAP Nuclear Translocation in Cholesteatoma}

An otoendoscopic examination revealed that the TM of the ears with cholesteatoma was retracted with debris, compared to that of normal ears (Figure 4A). Hematoxylin and eosin staining revealed hyperkeratinized, thickened epithelium and inflamed stromal tissue, or granular tissue with an infiltration of stromal cells composed mostly of fibroblasts

Figure 3 Analysis of negative-pressure model in rat middle ear. A: Otoendoscopic views of a negative-pressure ear and a control ear. Arrowheads indicate retraction of the tympanic membrane (TM) of the pars flaccida (PF). B: Hematoxylin and eosin staining of the TM of the PF in a negativepressure ear and a control ear. TM of the PF are thickened in the negative-pressure ears. Double-headed arrows indicate thickened epithelium; asterisks, thickened intermediate layer. C: Double immunostaining of Ilk (red) and Yap (brown) in the TM of the PF in the negative-pressure ear and control ear (boxed areas in B). The nuclei were stained with hematoxylin (blue). In the negative-pressure ear, $\mathrm{Ilk}^{+}$cells are mainly expressed in the basal and upper layers of the epidermal and intermediate layers. Yap nuclear translocation is observed in epithelial cells, and some of them are Ilk ${ }^{+}$ (black arrows). $\mathrm{Ilk}^{+} / \mathrm{Yap}^{-}$cells (red arrows) are mainly observed in stroma. In the control ears, $\mathrm{Ilk}^{+} / \mathrm{Yap}^{+}$cells are scarcely detected. Ki-67 $7^{+}$cells are detected in the basal layer of the epithelium and in the intermediate layer of the negative-pressure ear. In the control ear, Ki-67 ${ }^{+}$cells are rarely detected. Negative control was obtained by normal mouse (Ms) IgG and normal rabbit (Rb) IgG instead of first antibodies. Dashed lines indicate basement membrane. Boxed areas are shown at higher magnification to the right. D: The labeling index (LI) of Ilk ${ }^{+} /$Yap nuclear translocation in epithelial cells of the epidermal layer in the negative-pressure group versus the control group. E: The LI of Ki-67 in the epithelial layer of the TM in the negative-pressure ear versus the control ear. F: Double immunofluorescence detection of Ki-67 (green) and L1cam (red) in the TM of the PF in the negative-pressure ear and control ear (boxed areas in B). The nuclei were stained with DAPI (blue). Ki-67 ${ }^{+}$cells are detected in the epithelial and intermediate layers (green arrows) and L1cam ${ }^{+}$cells (red arrows) are detected mainly in the intermediate layer of the TM in the negative-pressure ear. In the control ear, $\mathrm{Ki}-67^{+}$and $\mathrm{L}_{1 \mathrm{cam}}{ }^{+}$cells are rarely detected. Dashed lines indicate basement membrane. Boxed areas are shown at higher magnification to the right. G: The LI of L1cam in the intermediate layer of the TM in the negative-pressure ear versus control ear. Data are expressed as means \pm SD. Error bars indicate $95 \%$ confidence interval. $n=4$ negative pressure; $n=5$ control. ${ }^{* * *} P<0.0001$. Scale bars $=20 \mu \mathrm{m}$. 


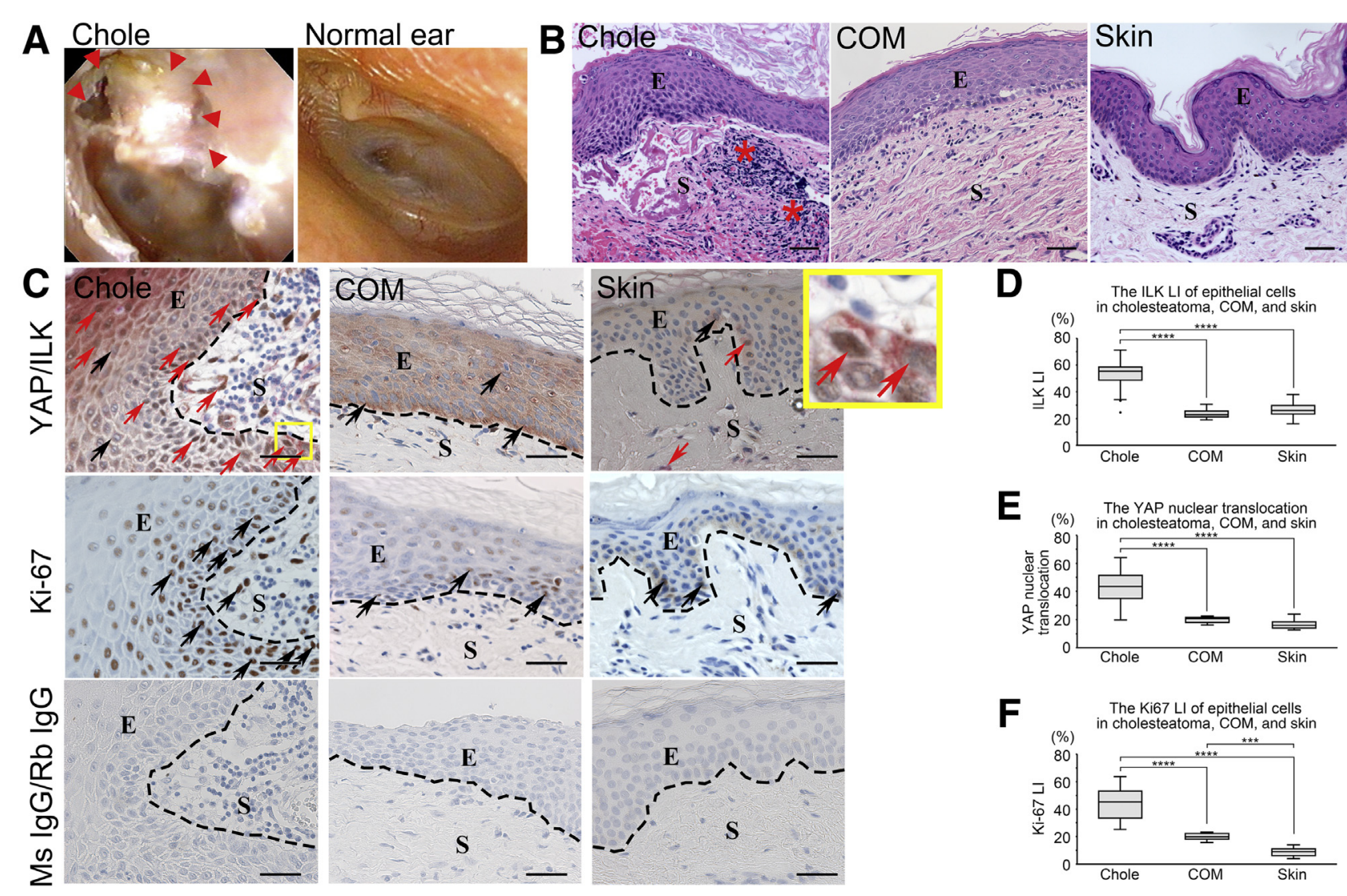

Figure 4 Analysis of human middle-ear cholesteatoma. A: Otoendoscopic views of middle ear cholesteatoma (chole) and normal ear. Arrowheads: retraction of the tympanic membrane of the pars flaccida. B: Hematoxylin and eosin staining of chole, chronic otitis media (COM), and normal ear skin (skin). The thickened epithelium and stroma with many infiltrated cells (asterisks) are shown in chole. C: Double staining for integrin-linked protein kinase (ILK) (red) and Yes-associated protein (YAP) (brown) and immunostaining for Ki-67 in formalin-fixed, paraffin-embedded sections of chole, COM, and skin. The nuclei were stained with hematoxylin (blue). ILK is mainly expressed in the basal and upper layers of the epithelium in chole and YAP nuclear translocation is observed in those cells (ILK ${ }^{+}$/nuclear YAP ${ }^{+}$; red arrows). ILK $/$cytoplasmic YAP ${ }^{+}$epithelial cells (black arrows in YAP/ILK) were observed in the COM. The positive cells are scarcely detected in the skin. Ki-67 positive cells (black arrows in Ki-67) are detected in basal and suprabasal layer, but are not detected in upper layer of epithelium of Chole. In the COM specimens, Ki-67-positive cells are detected mainly in the basal layers in the epithelium. A small number of Ki-67-positive cells are found in the normal skin section. Negative control was obtained by normal mouse (Ms) IgG and normal rabbit (Rb) IgG instead of first antibodies. Boxed area is shown at higher magnification to the right. Dashed lines indicate basement membrane. D-F: The labeling indexes (LI) of ILK (D), YAP nuclear translocation (E), and Ki-67 (F) in chole versus COM versus skin. Data are expressed as means \pm SD. Error bars indicate $95 \%$ confidence interval. $n=13 \mathrm{COM} ; n=25$ chole and skin. ${ }^{* *} P<0.001,{ }^{* * *} P<0.0001$. Scale bars $=20 \mu \mathrm{m}$. E, epithelial region; $\mathrm{S}$, stromal region.

and infiltrating lymphocytes in the cholesteatoma tissue. However, the COM showed thickened epithelium and stromal tissue with collagen fibers, and the normal ear skin tissue showed a normal squamous epithelium and stroma with no infiltrating cells (Figure 4B).

As expected, high expression of ILK and YAP nuclear translocation was significantly detected in the basal and upper layers of the epithelium of the cholesteatoma tissue. In the sections of cholesteatoma tissue, $\mathrm{ILK}^{+} / \mathrm{YAP}$ nucleartranslocated cells were mainly detected in the basal and upper layers of the epithelium (Figure 4C). In the suprabasal layer of the epithelium of the cholesteatoma tissues, both $\mathrm{ILK}^{+} / \mathrm{YAP}$ nuclear-translocated cells (Figure 4C) and $\mathrm{ILK}^{-} /$cytoplasmic-YAP expressed cells were detected (Figure 4C). However, ILK ${ }^{+}$cells were scarcely detected and YAP was observed in the cytoplasm of those cells in the $\mathrm{COM}$ (Figure $4 \mathrm{C}$ ). $\mathrm{ILK}^{+}$cells were observed only weakly in the epithelium of the normal skin tissue, and some of these cells showed YAP nuclear transduction (Figure 4C). Interestingly, in the stromal region, $\mathrm{ILK}^{+}$cells with YAP nuclear translocation were observed both in the cholesteatoma tissue and normal skin tissue but not in the COM tissue (Figure 4C). The ILK LI in the cholesteatoma tissue was significantly higher than that of the COM and the normal skin $(53.0 \% \pm 10.9 \%$ versus $23.5 \% \pm 3.23 \%$ and $26.7 \% \pm 5.06 \%$, respectively; both, $P<0.0001$, Tukey post hoc tests) (Figure 4D). The nuclear translocated-YAP LI in the cholesteatoma tissue was significantly higher than that of the COM and the normal skin tissue $(43.1 \% \pm 10.6 \%$ versus $19.9 \% \pm 2.12 \%$ and $16.4 \% \pm 5.21 \%$, respectively; both, $P<0.0001$, Tukey post hoc tests) (Figure 4E). The large numbers of $\mathrm{Ki}-67^{+}$cells were detected in basal and suprabasal layers of the epithelium in the cholesteatoma specimens (Figure 4C). In the COM specimens, Ki-67 


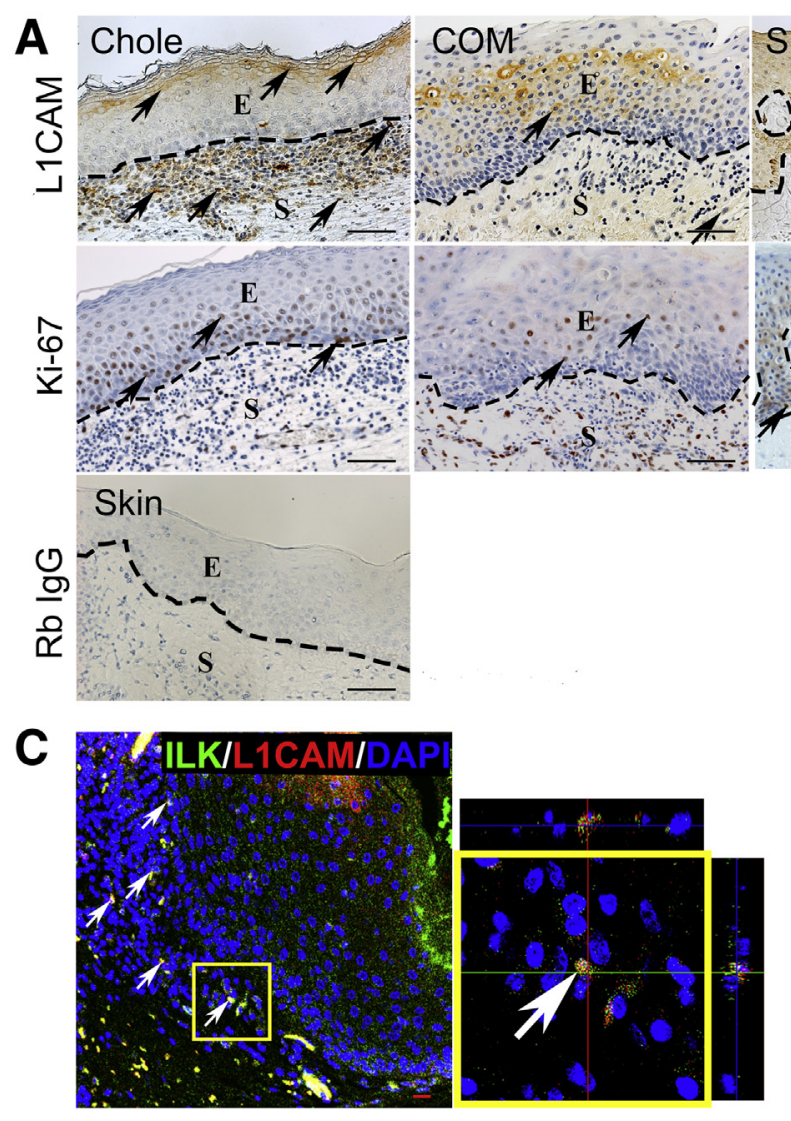

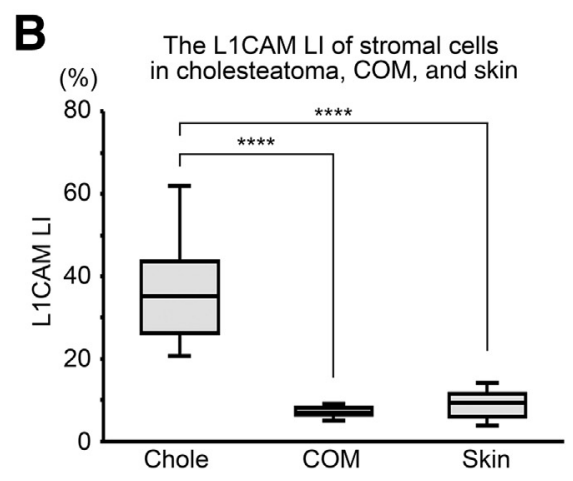

Figure 5 A: Immunohistochemistry analysis of L1 cell adhesion molecule (L1CAM) and Ki-67 in middle ear cholesteatoma (Chole), chronic otitis media (COM), and skin tissues. L1CAM $^{+}$cells (arrows in L1CAM) are detected mainly in the stroma of chole. A small number of $\mathrm{LICAM}^{+}$cells are detected in epithelium and stroma in the COM tissue, and all epithelial cells are $\mathrm{LICAM}^{+}$in the skin tissue. $\mathrm{Ki}-67^{+}$cells (arrows in Ki-67) are detected in the basal and suprabasal layers but not detected in the upper layer of epithelium in the cholesteatoma tissues. Negative control was obtained by normal rabbit (Rb) IgG. Dashed lines indicate basement membrane. B: The labeling index (LI) of L1CAM of stromal cells in chole versus COM versus skin. C: Double immunofluorescence detection of ILK (green) and L1CAM (red) in sections of chole. ILK and L1CAM coexpression (arrows) are detected in the basal layer of the epithelium in chole. The boxed area corresponds to the high-power view with $z$-stack images, orthogonal display, $x y, y z$, and $x z$ options shown to the right. Data are expressed as means \pm SD. Error bars indicate $95 \%$ confidence interval. $n=13$ COM; $n=25$ chole and skin. ${ }^{*} * * P<0.0001$. Scale bars $=20 \mu \mathrm{m}$. E, epithelial region; $\mathrm{S}$, stromal region. cells were found mainly in the basal layer, while some Ki$67^{+}$cells were found in upper layers, of the epithelium (Figure 4C). In the epithelium of the normal skin specimens, a small number of $\mathrm{Ki}-67^{+}$cells were found only in the basal layer (Figure 4C). The Ki-67 LI in the cholesteatoma tissue was significantly higher than that of the COM and the normal skin tissue $(44.8 \% \pm 11.2 \%$ versus $20.2 \% \pm 2.36 \%$ and $8.77 \% \pm 2.93 \%$, respectively; both, $P<0.0001$, Tukey post hoc tests) (Figure 4F).

\section{Analysis of L1CAM LI and Double Immunofluorostaining of L1CAM and ILK in Cholesteatoma}

In the epithelial layer of the normal skin tissues, $\mathrm{L}_{1 \mathrm{CAM}}^{+}$ cells were detected in all layers of the epithelium but scarcely detected in the stroma (Figure 5A). A small number of $\mathrm{L} 1 \mathrm{CAM}{ }^{+}$cells were detected in epithelium and stroma in the COM tissues (Figure 5A). However, in the thickened epithelial region of the cholesteatoma tissue, many $\mathrm{L}_{1 \mathrm{CAM}}{ }^{+}$ cells were detected in the stroma and upper layer of the epithelium (Figure 5A). Ki-67 $7^{+}$cells were detected in the basal and suprabasal layers but not detected in the upper layer of epithelium in the cholesteatoma tissues (Figure 5A). The L1CAM LI of the stromal cells in the cholesteatoma tissue was significantly higher than that of the COM and normal skin $(36.4 \% \pm 11.0 \%$ versus $7.15 \% \pm 1.11 \%$ and $9.05 \pm 3.14 \%$, respectively; both, $P<0.0001$, Tukey post hoc test) (Figure 5B). To identify the interaction of ILK and L1CAM in epithelial cells and/or stromal cells in the cholesteatoma tissue, double immunofluorostaining of L1CAM and ILK was performed, and z-stack images were taken using confocal laser scanning microscopy. The coexpression of ILK and L1CAM was detected in the intercellular region of some cells in the basal layer of the epithelium in the cholesteatoma tissue (Figure 5C). According to the results of the high-power view, the z-stack image indicated that L1CAM and ILK were detected in the cell-cell interaction space (Figure 5C). These findings indicate the possibility that L1CAM expressed in a stromal cell attached to a basal cell in the epithelial region activates ILK signaling in cholesteatoma tissue.

\section{Correlation between L1CAM Expression and Ki-67 LI in Cholesteatoma}

To analyze the association between L1CAM expression and the proliferative activity of epithelial cells in cholesteatoma tissue, the LI of L1CAM was characterized as either high (L1CAM LI $>50 \%, n=4)$, moderate $(50 \%>$ L1CAM LI $>30 \%, n=13$ ), or low (L1CAM LI $<30 \%, n=8$ ), and IHC analysis for Ki-67 was performed in each group. In the 


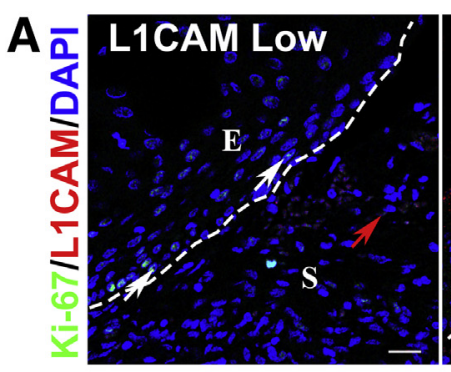

B

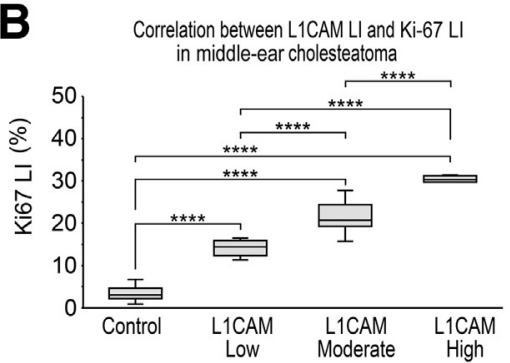

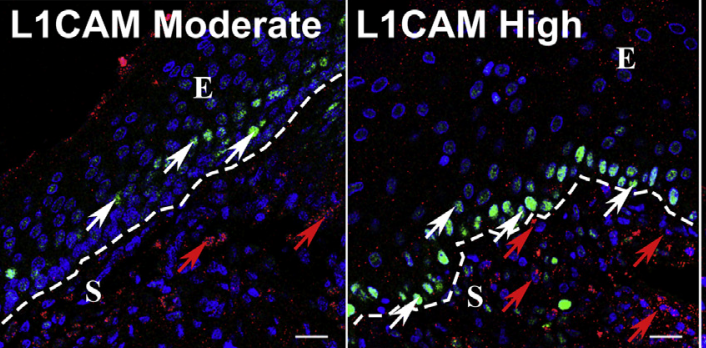
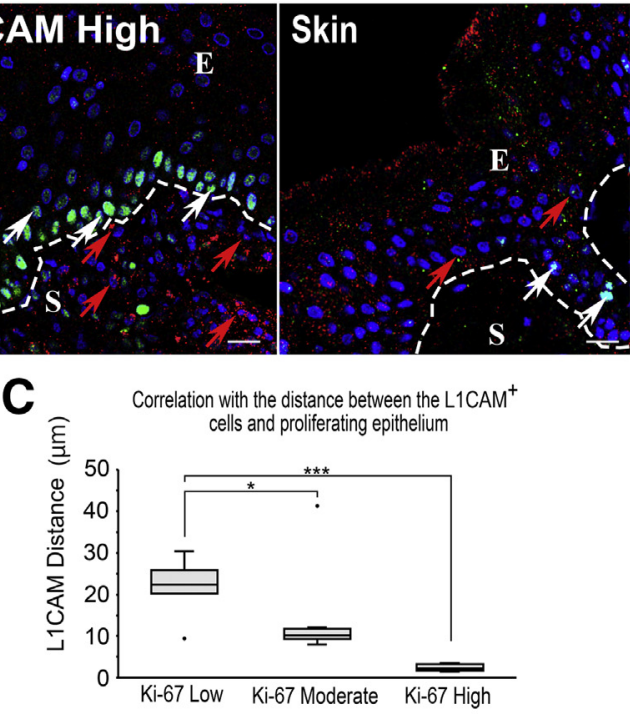

Figure 6 Correlation between the labeling indexes (LI) of L1 cell adhesion molecule (L1CAM) and Ki-67 in cholesteatoma (chole). A: Double immunofluorescence detection of Ki-67 (green) and L1CAM (red). The nuclei were stained with DAPI (blue). Ki-67 ${ }^{+}$cells (white arrows) are detected in the epithelial layer, and $\mathrm{LICAM}^{+}$cells (red arrows) are detected in the stromal layer of chole. Dashed lines indicate basement membrane. B: Correlation between L1CAM and Ki-67 LIs of the epithelium in each group. L1CAM low, L1CAM LI <30\%; L1CAM moderate, 30\% < L1CAM LI < 50\%; L1CAM high, L1CAM LI >50\%. C: Correlation between L1CAM distance and Ki-67 LI in chole. Ki-67 LI low, Ki-67 LI <30\%; Ki-67L1 moderate, 30\% < Ki-67 LI < $50 \%$; Ki-67 high, Ki-67 LI $>50 \%$. Data are expressed as means \pm SD. Error bars indicate $95 \%$ confidence interval. $n=4$ L1CAM high (B) and Ki-67 high (C); $n=8$ L1CAM low (B) and Ki67 LI low (C); $n=13$ L1CAM moderate (B) and Ki-67L1 moderate (C); $n=25$ skin (B and C). ${ }^{*} P<0.05, * * * P<0.001$, and ${ }^{* * *} P<0.0001$. Scale bars $=20$ $\mu \mathrm{m}$. E, epithelial region; $\mathrm{S}$, stromal region; skin, normal ear skin.

epithelium of the normal skin specimens and the low L1CAM group, $\mathrm{Ki}-67^{+}$cells were found only in the basal layer (Figure 6A). In the high and moderate L1CAM groups, $\mathrm{Ki}-67^{+}$cells were found in the basal and suprabasal layers in the epithelium (Figure 6A). The Ki-67 LI of the high L1CAM group $(30.4 \% \pm 0.81 \%)$ was significantly higher than that in all of the other groups (moderate group, $21.5 \% \pm 3.37 \%$; low group, $14.1 \% \pm 1.84 \%$; skin, $3.38 \% \pm 1.70 \%$ ) (all, $P<0.0001$, Tukey post hoc test). The Ki-67 LI of the moderate L1CAM group was significantly higher than that of the low group and skin $(P<0.0001$, Tukey post hoc test) (Figure 6B). The LI of Ki-67 was characterized as high (Ki-67 LI $>50 \%, n=4)$, moderate $(50 \%>\mathrm{Ki}-67 \mathrm{LI}>30 \%, n=13)$, or low (Ki-67 LI $<30 \%$, $n=8)$ and the level of L1CAM distance was compared between each group. The L1CAM distance of the high $\mathrm{Ki}$ 67 LI group was significantly lower than that of the low Ki-67 LI group $(2.38 \pm 0.81$ versus $22.0 \pm 6.08 \mu \mathrm{m}$; $P<0.001$, Tukey post hoc test). The level of L1CAM distance of the moderate $\mathrm{Ki}-67 \mathrm{LI}$ group was significantly lower than that of the low Ki-67 LI group $(12.5 \pm 8.73$ versus $22.0 \pm 6.08 \mu \mathrm{m} ; P<0.05$, Tukey post hoc test) (Figure 6C).

\section{Uniaxial Stretch and Epithelial Cell Proliferation Activity under rm L1CAM}

As expected, many $\mathrm{Ki}-67^{+}$cells were detected in the section of the stretched with rm L1cam group (Figure 7A). The LI of the Ki- $67^{+}$cells in the section of the stretched with rm
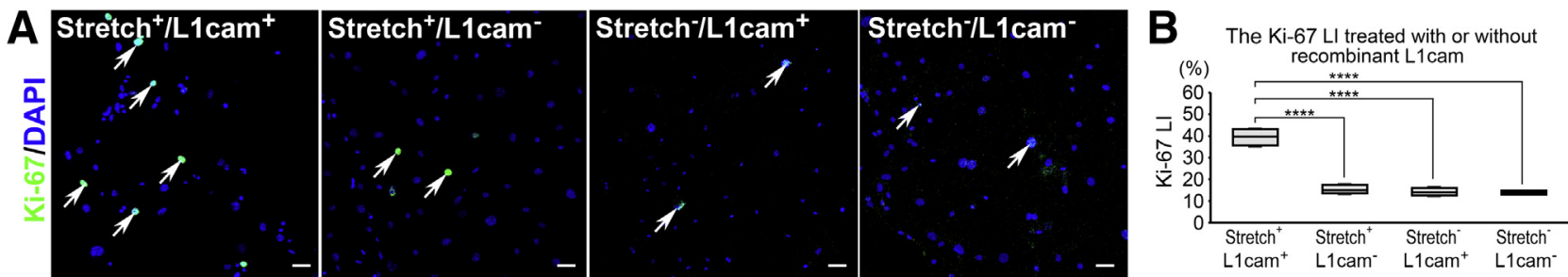

Figure 7 A: Quantitation of Ki-67 ${ }^{+}$cells (arrows) of stretched or nonstretched mouse epithelial cells untreated and treated with recombinant mouse ( $\mathrm{rm}$ ) L1cam $(30 \mu \mathrm{g} / \mathrm{mL})$ for 24 hours. Immunofluorescence detection of Ki-67 (green). The nuclei were stained with DAPI (blue). Many Ki-67 cells are detected in the cells stretched with rm L1cam. B: The Ki-67 labeling index (LI) of cells in each group. Data are expressed as means \pm SD. Error bars indicate $95 \%$ confidence interval. ${ }^{* * *} P<0.0001$. Scale bars $=20 \mu \mathrm{m}$. 
L1cam group $(35.2 \% \pm 1.83 \%)$ was significantly higher than those of the other groups (stretched without rm L1cam group, $15.3 \% \pm 2.21 \%$; nonstretched with $\mathrm{rm} \mathrm{L1cam}$ group, $13.8 \% \pm 0.93 \%$; nonstretched without rm L1cam group, $14.1 \% \pm 1.79 \%$ ) (all, $P<0.0001$, Tukey post hoc test) (Figure 7B).

\section{Discussion}

Middle-ear cholesteatoma is characterized by the presence of keratinizing epithelium that is believed to have hyperproliferative properties. ${ }^{26}$ However, our understanding of the molecular mechanisms underlying the pathogenesis of cholesteatoma is limited. In this study, we first demonstrated the mechanotransductal pathway under high Ilk expression and Yap nuclear translocation in a stretched primary culture of mouse middle-ear epithelial cells. Recently, Gudipaty et $\mathrm{al}^{27}$ indicated that mechanical stretching rapidly stimulates cell division and proliferation by experimentally stretching epithelial monolayer cells. However, in the stretched assay of the current study, mitotic cells were rarely detected, because cell-cell junctions and the monolayer structure were not parts of the primary culture methods. In fact, L1cam expression was decreased in the stretched primary culture cells. Next, Ilk expression and Yap nuclear translocation were examined in stretched epithelium in vivo. As a result, $\mathrm{Ilk}^{+} /$Yap nucleartranslocated cells were detected in the basal and upper layers of the epithelium and a significantly higher proliferative activity of epithelial cells was observed in the TM of negative-pressure-load ears. In vivo studies of stretched skin have indicated that tension due to stretching increases the mitotic activity of the epidermis, leading to an increased progenitor cell population and subsequent tissue hyperplasia-the same as results from the current study. ${ }^{28}$ However, $\mathrm{Ki}-67^{+}$cells were detected in the basal layer but not in upper layer of the epithelium of the negativepressure ears. Recent work has indicated that attached cells expressing L1CAM combine with epithelial cells expressing ILK and up-regulate the nuclear translocation of YAP in epithelial cells and induce proliferating activity of epithelial cells. ${ }^{12}$ According to these facts, we postulated that $\mathrm{Ilk}^{+} /$Yap nuclear-translocated cells in the basal layer that were near the $\mathrm{L} 1 \mathrm{cam}^{+}$stromal cells might indicate the high expression of mechanotransduction pathway-related molecules L1cam, Ilk, and Yap to induce proliferative activity of cells in a negative-pressure animal model. ${ }^{13,14}$ On the other hand, another recent study showed that ILK is an essential component of keratinocyte differentiation in the upper layer of skin. ${ }^{29}$ Therefore, ILK ${ }^{+} /$YAP nuclear translocation of cells might play a role in differentiation in the upper layer of the epithelium. Indeed, this study could show the same results in human cholesteatoma specimens. A lot of $\mathrm{ILK}^{+} /$YAP nuclear-translocated cells were observed on the upper and basal layers of the epithelium; on the other hand, Ki- $67^{+}$cells were detected in the basal and suprabasal layers but not in the upper layer of the epithelium of cholesteatoma specimens.

L1CAM, working in coordination with classic transcription factors, stimulates proliferation and induces the maintenance of self-renewal and pluripotency of stem cells. ${ }^{30}$ L1CAM immunoreactivity has been clearly detected in the epidermis within the basal and spinous layers, but not detected in the dermal layer of the normal skin, to affect the differentiation and maintenance of epithelial tissues. ${ }^{31}$ These results also indicate that $\mathrm{L}_{1} \mathrm{CAM}^{+}$cells were mainly detected in the basal and spinous layers of the epithelium of the normal skin and upper layer of the epithelium of human cholesteatoma specimens. Meanwhile, the role of L1CAM is different in cancer cells. L1CAM concentrates in the peripheral cells, sustaining proliferation, invasion, and metastasis in many cancers. ${ }^{9,12,32}$ Interestingly, in the human cholesteatoma specimens, a huge number of $\mathrm{L} \mathrm{CAM}^{+}$cells were detected in the stroma, and some beside the epithelium. Moreover, YAP nuclear translocation was observed in most of the $\mathrm{ILK}^{+}$cells in the thickened epithelium of the cholesteatoma tissue. These results indicate that the mechanical cues of negative pressure in the middle ear may activate the stromal L1CAM-epithelial ILK signaling pathway to complete cholesteatoma formation or progression. A high LI of stromal $\mathrm{L}_{1 C A M}{ }^{+}$cells was significantly correlated with the proliferative activity of epithelial cells in cholesteatoma tissue. Indeed, a recent study demonstrated that the L1CAM expression rate in cancer specimens was correlated with cancer cell proliferation and survival rates, which also supports these results. ${ }^{33}$ L1CAM has unique signaling processes based on its interaction with and activation of growth factor receptors. The binding of specific motifs identified in the ectodomains of L1CAM has been shown to induce the activation of fibroblast growth factor receptors, including keratinocyte growth factor receptor. ${ }^{34}$ Indeed, previous studies revealed the expression of keratinocyte growth factor receptor in the epithelium of cholesteatoma tissue with high proliferative activity. ${ }^{22,23,31}$ This study also found an increase in the proliferative activity of middle-ear cells with soluble L1CAM protein under mechanical conditions. According to these findings, in cholesteatoma, soluble L1CAM ectodomain expressed in stromal cells might bind to keratinocyte growth factor receptor in epithelial cells. As a result, epithelial cell proliferation would be induced.

We hypothesized that mechanotransductal stimuli might induce $\mathrm{ILK}^{+} / \mathrm{YAP}$ nuclear translocation in the epithelial cells and trigger cell proliferation; however, as a result, epithelial proliferation was not induced without stromal L1CAM expression. In conclusion, we demonstrated that the L1CAM-ILK-YAP signaling pathway plays an essential role in epithelial growth under mechanotransduction during acquired middle-ear cholesteatoma formation. L1CAM could be a therapeutic target for this 
disease, although further studies are necessary to elucidate the role of L1CAM-ILK-YAP signaling in the pathophysiology of cholesteatoma.

\section{Acknowledgments}

We thank Masahiro Takahashi, Kazuhisa Yamamoto, and Yutaka Yamamoto (Jikei University School of Medicine) for the harvesting of the human tissues; and Eika Hayashi and Yoshiyuki Kasai (Jikei University School of Medicine) for their excellent technical assistance in this work.

\section{References}

1. Magnuson K, Hellstrom S, Magnuson B: Structural changes in the rat tympanic membrane following repeated pressure loads. Eur Arch Otorhinolaryngol 1995, 252:76-82

2. Ohta S, Sakagami M, Suzuki M, Mishiro Y: Eustachian tube function and habitual sniffing in middle ear cholesteatoma. Otol Neurotol 2009, 30:48-53

3. Piccolo S, Dupont S, Cordenonsi M: The biology of YAP/TAZ: Hippo signaling and beyond. Physiol Rev 2014, 94:1287-1312

4. Chen D, Sun Y, Wei Y, Zhang P, Rezaeian AH, TeruyaFeldstein J, Gupta S, Liang H, Lin HK, Hung MC, Ma L: LIFR is a breast cancer metastasis suppressor upstream of the HippoYAP pathway and a prognostic marker. Nat Med 2012, 18: $1511-1517$

5. Benham-Pyle BW, Pruitt BL, Nelson WJ: Cell adhesion. Mechanical strain induces E-cadherin-dependent YAP1 and betacatenin activation to drive cell cycle entry. Science 2015, 348: 1024-1027

6. Dupont S: Role of YAP/TAZ in cell-matrix adhesion-mediated signaling and mechanotransduction. Exp Cell Res 2016, 343:42-53

7. Serrano I, McDonald PC, Lock F, Muller WJ, Dedhar S: Inactivation of the Hippo tumour suppressor pathway by integrin-linked kinase. Nat Commun 2013, 4:2976

8. Elbediwy A, Vincent-Mistiaen ZI, Spencer-Dene B, Stone RK, Boeing S, Wculek SK, Cordero J, Tan EH, Ridgway R, Brunton VG, Sahai E, Gerhardt H, Behrens A, Malanchi I, Sansom OJ, Thompson BJ: Integrin signalling regulates YAP and TAZ to control skin homeostasis. Development 2016, 143: $1674-1687$

9. Colombo F, Meldolesi J: L1-CAM and N-CAM: from adhesion proteins to pharmacological targets. Trends Pharmacol Sci 2015, 36: 769-781

10. Schäfer MK, Altevogt P: L1-CAM malfunction in the nervous system and human carcinomas. Cell Mol Life Sci 2010, 67: $2425-2437$

11. Kiefel H, Bondong S, Hazin J, Ridinger J, Schirmer U, Riedle S, Altevogt P: L1-CAM: a major driver for tumor cell invasion and motility. Cell Adh Migr 2012, 6:374-384

12. Er EE, Valiente M, Ganesh K, Zou Y, Agrawal S, Hu J, Griscom B, Rosenblum M, Boire A, Brogi E, Giancotti FG, Schachner M, Malladi S, Massagué J: Pericyte-like spreading by disseminated cancer cells activates YAP and MRTF for metastatic colonization. Nat Cell Biol 2018, 20:966-978

13. Akiyama N, Yamamoto-Fukuda $\mathrm{T}$, Takahashi $\mathrm{H}$ : Influence of continuous negative pressure in the rat middle ear. Laryngoscope 2014, 124:2404-2410

14. Akiyama N, Yamamoto-Fukuda T, Yoshikawa M, Kojima H: Evaluation of YAP signaling in a rat tympanic membrane under a continuous negative pressure load and in human middle ear cholesteatoma. Acta Otolaryngol 2017, 137:1158-1165
15. Akiyama N, Yamamoto-Fukuda T, Takahashi H, Koji T: In situ tissue engineering with synthetic self-assembling peptide nanofiber scaffolds, PuraMatrix, for mucosal regeneration in the rat middle-ear. Int $\mathrm{J}$ Nanomedicine 2013, 8:2629-2640

16. Kurita M, Okazaki M, Fujino T, Takushima A, Harii K: Cyclic stretch induces upregulation of endothelin-1 with keratinocytes in vitro: possible role in mechanical stress-induced hyperpigmentation. Biochem Biophys Res Commun 2011, 409:103-107

17. Iwata M, Hayakawa K, Murakami T, Naruse K, Kawakami K, Inoue-Miyazu M, Yuge L, Suzuki S: Uniaxial cyclic stretchstimulated glucose transport is mediated by a Ca-dependent mechanism in cultured skeletal muscle cells. Pathobiology 2007 74:159-168

18. Sasamoto A, Nagino M, Kobayashi S, Naruse K, Nimura Y, Sokabe M: Mechanotransduction by integrin is essential for IL-6 secretion from endothelial cells in response to uniaxial continuous stretch. Am J Physiol Cell Physiol 2005, 288: C1012-C1022

19. Cui Y, Hameed FM, Yang B, Lee K, Pan CQ, Park S, Sheetz M: Cyclic stretching of soft substrates induces spreading and growth. Nat Commun 2015, 6:6333

20. Angiolini F, Belloni E, Giordano M, Campioni M, Forneris F, Paronetto MP, Lupia M, Brandas C, Pradella D, Di Matteo A, Giampietro C, Jodice G, Luise C, Bertalot G, Freddi S, Malinverno M, Irimia M, Moulton JD, Summerton J, Chiapparino A, Ghilardi C, Giavazzi R, Nyqvist D, Gabellini D, Dejana E, Cavallaro U, Ghigna C: A novel L1CAM isoform with angiogenic activity generated by NOVA2mediated alternative splicing. Elife 2019, 8:e44305

21. Yamamoto-Fukud $T$, Shibata $Y$, Hishikawa $Y$, Shin $M$, Yamaguchi A, Kobayashi T, Koji T: Effects of various decalcification protocols on detection of DNA strand breaks by terminal dUTP nick end labelling. Histochem J 2000, 32:697-702

22. Yamamoto-Fukuda T, Aoki D, Hishikawa Y, Kobayashi T, Takahashi H, Koji T: Possible involvement of keratinocyte growth factor and its receptor in enhanced epithelial-cell proliferation and acquired recurrence of middle-ear cholesteatoma. Lab Invest 2003, $83: 123-136$

23. Yamamoto-Fukuda T, Akiyama N, Takahashi M, Kojima H: Keratinocyte growth factor (KGF) modulates epidermal progenitor cell kinetics through activation of p63 in middle ear cholesteatoma. J Assoc Res Otolaryngol 2018, 19:223-241

24. Abel EJ, Bauman TM, Weiker M, Shi F, Downs TM, Jarrard DF Huang W: Analysis and validation of tissue biomarkers for renal cell carcinoma using automated high-throughput evaluation of protein expression. Hum Pathol 2014, 45:1092-1099

25. Schneider CA, Rasband WS, Eliceiri KW: NIH Image to ImageJ: 25 years of image analysis. Nat Methods 2012, 9:671-675

26. Sudhoff H, Tos M: Pathogenesis of attic cholesteatoma: clinical and immunohistochemical support for combination of retraction theory and proliferation theory. Am J Otol 2000, 21:786-792

27. Gudipaty SA, Lindblom J, Loftus PD, Redd MJ, Edes K, Davey CF, Krishnegowda V, Rosenblatt J: Mechanical stretch triggers rapid epithelial cell division through Piezo1. Nature 2017, 543:118-121

28. Pietramaggiori G, Liu P, Scherer SS, Kaipainen A, Prsa MJ, Mayer H, Newalder J, Alperovich M, Mentzer SJ, Konerding MA, Huang S, Ingber DE, Orgill DP: Tensile forces stimulate vascular remodeling and epidermal cell proliferation in living skin. Ann Surg 2007, 246:896-902

29. Sayedyahossein S, Rudkouskaya A, Leclerc V, Dagnino L Integrin-linked kinase is indispensable for keratinocyte differentiation and epidermal barrier function. J Invest Dermatol 2016, $136: 425-435$

30. Son YS, Seong RH, Ryu CJ, Cho YS, Bae KH, Chung SJ, Lee B, Min JK, Hong HJ: Brief report: L1 cell adhesion molecule, a novel surface molecule of human embryonic stem cells, is 
essential for self-renewal and pluripotency. Stem Cells 2011, 29: 2094-2099

31. Nolte C, Moos M, Schechter M: Immunolocalization of the neural cell adhesion molecule L1 in epithelia of rodents. Cell Tissue Res 1999, 298:261-273

32. Pietilä M, Ivaska J, Mani SA: Whom to blame for metastasis, the epithelial-mesenchymal transition or the tumor microenvironment? Cancer Lett 2016, 380:359-368
33. Tischler V, Pfeifer M, Hausladen S, Schirmer U, Bonde AK, Kristiansen G, Sos ML, Weder W, Moch H, Altevogt P, Soltermann A: L1CAM protein expression is associated with poor prognosis in non-small cell lung cancer. Mol Cancer 2011, 10: 127

34. Kiefel H, Pfeifer M, Bondong S, Hazin J, Altevogt P: Linking L1CAM-mediated signaling to NF-kB activation. Trends Mol Med 2011, 17:178-187 